\title{
Growth of Mytilus galloprovincialis after the Prestige oil spill
}

\author{
Laura G. Peteiro, José M. F. Babarro, Uxío Labarta, and \\ María José Fernández-Reiriz
}

Peteiro, L. G., Babarro, J. M. F., Labarta, U., and Fernández-Reiriz, M. J. 2006. Growth of Mytilus galloprovincialis after the Prestige oil spill. - ICES Journal of Marine Science, 63: 1005-1013.

Growth of mussel Mytilus galloprovincialis using raft culture was investigated for the first cultured generation following the Prestige oil spill off northwestern Spain. Seed from three natural populations along the Galician coastline, Pindo, Miranda, and Redes, was transplanted to a raft culture system in Ría de Ares-Betanzos. The physiological and biochemical status of mussels at the onset of culture and the degree of oil exposure three months after the spill (February 2003) have been described already, but here growth patterns of three populations sampled monthly from seeding to thinning-out (March/August 2003) and from thinning-out to harvest (August 2003/February 2004) were assessed. Mussels from Pindo (the area most affected by the oil spill) showed significantly less growth by weight than the other populations, resulting in a lower yield at harvest. The percentage of mussels classified as "large" in the Pindo population at harvest was also significantly less than that of the other two mussel populations.

(c) 2006 International Council for the Exploration of the Sea. Published by Elsevier Ltd. All rights reserved.

Keywords: growth, Mytilus galloprovincialis, Prestige spill, raft culture, sublethal effects.

Received 26 September 2005; accepted 22 March 2006.

L. G. Peteiro, J. M. F. Babarro, U. Labarta, and M. J. Fernández-Reiriz: Instituto de Investigaciones Marinas CSIC, Eduardo Cabello 6, 36208 Vigo, Spain. Correspondence to M. J. Fernández-Reiriz: tel: +34 986 231930, ext 207; fax: +34 986 292762; e-mail: mjreiriz@iim.csic.es.

\section{Introduction}

After the oil tanker Prestige sank near Cape Finisterre in November 2002, successive black waves affected a wide area of the Galician coastline (NW Spain). Although significant amounts of spilled oil did not enter the inner parts of Galician estuaries where commercial raft culture of mussels takes place, there was a significant effect along an extensive area of the coast where mussel seed is gathered for culture purposes. A hydrocarbon gradient in mussel seed tissues has been found in populations along the Galician coastline (Labarta et al., 2005), indicating that the most affected area is between Cape Finisterre and Ría de Pontevedra (Figure 1).

Bivalves, particularly mussels, are commonly used as sentinel organisms in helping to identify the status and trends of chemical exposure and pollution gradients in a variety of environments. Mussels are good sentinels of chemical exposure because they are sessile and filter the water for food. They are also widely distributed and respond to changes in the environment through physiological responses that are easily measurable. This facilitates the establishment of relationships between the concentration of chemicals in water, sediment, and tissues and associated biological effects (Salazar and Salazar, 1995; Dame, 1996). Such physiological effects, e.g. changes in biochemical composition (Livingston, 1985; Modassir and Ansari, 2000; Duquesne et al., 2004), or a decline in clearance rate, food absorption efficiency and respiration rate (Bayne et al., 1978; Widdows, 1978; Bayne, 1985; Widdows et al., 2002), as well as others have an effect on and are manifested in alterations in mussel growth. Growth integrates a number of internal biological processes of the animal, and is influenced by the environment and can be used as an index of stress (Salazar and Salazar, 1995). Both natural stress and that related to pollution have been linked to reduced growth rates in terms of both shell length and weight, although both these growth metrics may be influenced by different factors (Salazar and Salazar, 1995; Dame, 1996). Such patterns have been reported in several studies in which growth rates declined as a consequence of exposure of mussels to chemicals such as hydrocarbons, TBT, or heavy metals (Strömgren, 1982; Strömgren et al., 1986; Strömgren and Bongard, 1987; Salazar and Salazar, 1991; Guolan and Yong, 1995; Soto et al., 2000; Le Floch et al., 2003). 


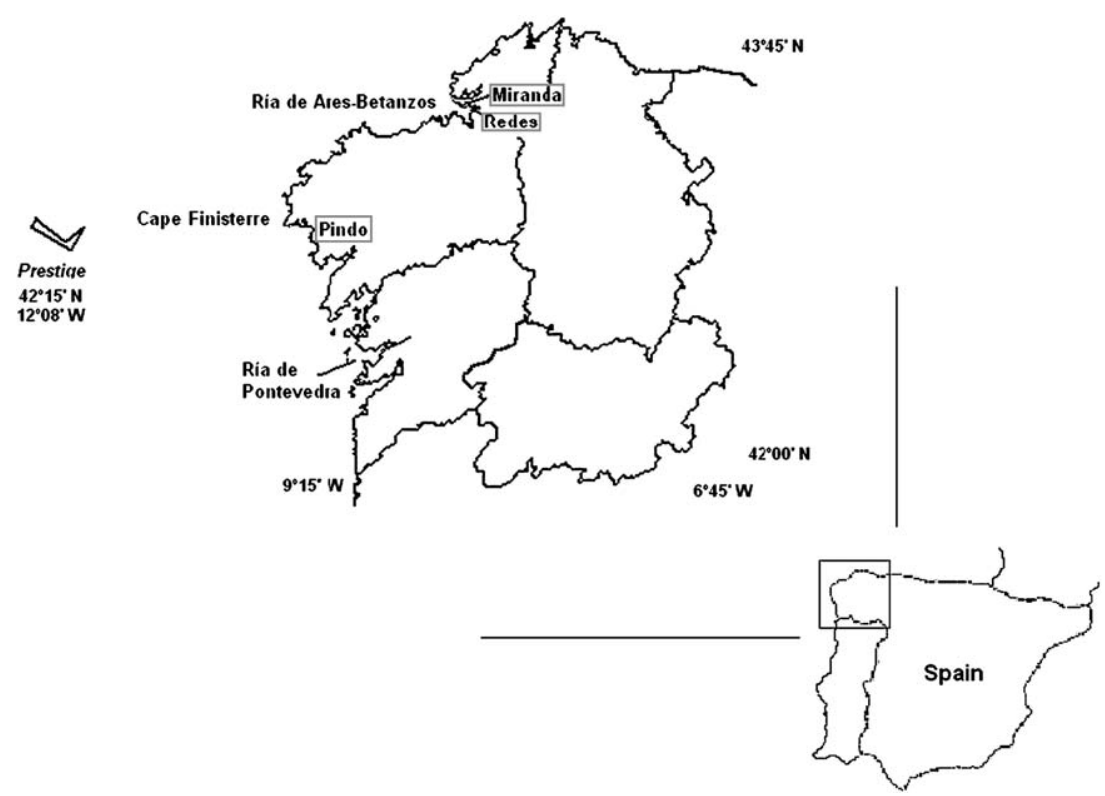

Figure 1. Map of Galicia (NW Spain) showing the three mussel seed origins, the location of the experimental culture (Ría de AresBetanzos), the site where the oil tanker Prestige sank, and the area most affected by the oil spill (between Cape Finisterre and Ría de Pontevedra).

Condition index (CI) may also be associated with episodes of stress that involve losses in weight of soft tissues, which in turn would be related to mobilization of energy reserves (Bayne, 1985; Dame, 1996; Modassir and Ansari, 2000). Nevertheless, condition index may be a weak indicator because of its variable response to chemicals. Although both growth rate and CI are influenced by similar environmental and endogenous factors, CI seems to be less sensitive than growth rate to chemical stress (Guolan and Yong, 1995), and CI variability is usually attributed to changes in food availability or gametogenic cycle (Hummel et al., 1996; Leung and Furness, 2001; Amiard et al., 2004; Boscolo et al., 2004; Pampanin et al., 2005).

A powerful tool for characterizing exposure and effects to chemicals is to study in an integrated manner the biological responses and chemical response of mussel tissues (Salazar and Salazar, 1991). In a previous study in which biochemical and physiological indicators were integrated with hydrocarbon concentrations in mussel tissues, Labarta et al. (2005) characterized sublethal effects among several mussel seed populations used for raft culture in Galicia, three months after the Prestige spill.

The aim of the present study was to characterize growth patterns in the first generation after the Prestige spill, and to identify parameters that can be linked to oil exposure in the locations commonly used for gathering mussel seed for raft culture. We selected three mussel populations (Miranda, Pindo, and Redes), because their initial biochemical and physiological status and their hydrocarbon exposure were known and specifically determined by Labarta et al. (2005). These mussel populations were transplanted from their original locations to Ría de Ares-Betanzos, where experimental raft culture following standard commercial techniques was carried out.

\section{Material and methods}

\section{Experimental design}

In March 2003, mussel seed Mytilus galloprovincialis was gathered from three locations along the Galician coastline: Pindo, Miranda, and Redes (Figure 1). Mussel seed came from rocky shore habitats (Pindo and Miranda) and from raft collector ropes (Redes). All sources of mussel seed were the first cultured generation after the Prestige oil spill. Experimental culture was carried out using a raft system usually employed for mussel culture in Ría de Ares-Betanzos $\left(500 \mathrm{~m}^{2}\right)$, with commercial protocols and techniques. Experimental culture began in early spring 2003, when gathering of mussel seed for culture was first allowed by the Spanish government, following the oil spill. Mussel culture lasted for one year, covering both phases of commercial culture in Galicia, from seeding to thinning-out (March to August 2003) and from thinning-out to harvest (August 2003 to February 2004). A number of two-rope pairs were employed for each mussel population, with a density of approximately $15 \mathrm{~kg}$ of mussel seed per rope, an average density commonly used in Galician raft culture (Pérez Camacho and Labarta, 2004), and placed at the prow of three adjacent rafts in the Lorbé polygon of Ría de Ares-Betanzos. Initial shell lengths (mean \pm s.d.) were $21.4 \pm 7.8,10.4 \pm 3.6$, and $15.6 \pm 6.7 \mathrm{~mm}$, and total dry 
weights were $0.329 \pm 0.002,0.074 \pm 0.001$, and $0.150 \pm$ $0.008 \mathrm{~g}$ for mussels originally from Redes, Miranda, and Pindo, respectively. Thinning-out was done in August 2003 when mussels reached shell lengths of some $50 \mathrm{~mm}$. This procedure has two main objectives: to reduce the density of the culture attributable to biomass increase by preparing new ropes from each mussel seed and to discard small mussels in order to obtain a uniform size at harvest (Pérez Camacho et al., 1991). We managed to obtain ten cultivation ropes from the initial six ropes in the thinning-out procedure (four ropes from two initial ropes of Redes seed, and three ropes from two initial ropes of Miranda and of Pindo).

\section{Mussel sampling}

Mytilus galloprovincialis were collected monthly from each rope and at 3-4 m deep, using two replicates of 200-300 mussels. Individual lengths were recorded as the maximum measure along the anterior-posterior axis to the nearest $0.1 \mathrm{~mm}$, using callipers (Mitutoyo ${ }^{\circledR}$ ), and each sample was divided into 1-mm length classes. Adjusted shell length was calculated by the formula $L=\left(C_{L} F\right) N^{-1}$ (Box et al., 1989), where $L$ is the average shell length, $C_{L}$ the length class, $F$ the frequency, and $N$ is the total number of mussels considered. All mussels within each shell length class were weighed live, with shells tightly closed, to obtain the whole animal wet weight including water trapped between the valves. From each replicate sample, subsamples of 12-15 mussels were selected from five length classes below and above the adjusted length in order to obtain total, tissue, and shell dry weight $\left(\mathrm{DW}_{\text {total }}, \mathrm{DW}_{\text {tissue, }}\right.$, and $\mathrm{DW}_{\text {shell, }}$, respectively). First, the adductor muscle was cut and mussels were placed with their ventral edge on filter paper to remove the internal water. After dissecting the tissue from the shell valves, both were dried at $110^{\circ} \mathrm{C}$ until constant weight was obtained, then soft tissues and shell were weighed separately to obtain $\mathrm{DW}_{\text {tissue }}$ and $\mathrm{DW}_{\text {shell. }}$ The total dry weight is calculated as the sum of tissue and shell dry weights.

Condition index $(\mathrm{CI})$ was calculated for each replicate sample using the formula $\mathrm{CI}=\left(\mathrm{DW}_{\text {tissue }} / \mathrm{DW}_{\text {shell }}\right) \times 100$ (Freeman, 1974).

\section{Environmental parameters}

Chlorophyll $a\left(\mu \mathrm{g}^{-1}\right)$, temperature $\left({ }^{\circ} \mathrm{C}\right)$, and salinity here refer to average values measured $4 \mathrm{~m}$ deep at three sites in the experimental area by the Marine Environment Quality Control Centre of the Consellería de Pesca e Asuntos Mariños of the Xunta de Galicia, and published in their periodical reports.

\section{Data analysis}

Weights that corresponded to the adjusted shell length were calculated by regression models of log-transformed total, tissue, and shell dry weight (DW) against log-transformed length $(L)$, following the formula: $\log \mathrm{DW}=\log a+b \log L$. Regression models were calculated from the length and weight data collected monthly.

Frequency distributions of the size classes for each sample and origin of mussels were fitted to unimodal or bimodal distributions according to the goodness-of-fit (Babarro et al., 2003), using an extra sum-of-squares $F$ test for comparing models to choose the best fit (Motulsky and Christopoulos, 2004).

Shell length growth curves were fitted to a Gompertz model: $L_{t}=L_{\infty}\left(\mathrm{e}^{-\mathrm{e}^{\left(-k\left(t-t^{\prime}\right)\right)}}\right)$, where $L_{t}$ is the shell length (mm) at time $t$ (months), $L_{\infty}$ the maximum size, $k$ the growth parameter indicator of the speed at which maximum size is attained, and $t^{\prime}$ is the inflexion point of the curve (Ratkoskwy, 1990). In a similar way, total dry weight growth curves were also fitted to Gompertz model: $\mathrm{DW}_{t}=\mathrm{DW}_{\infty}\left(\mathrm{e}^{-\mathrm{e}^{\left(-k\left(t-t^{\prime}\right)\right)}}\right)$, parameters of the DW equation being analogous to those of the shell length equation. The Gompertz model parameters were estimated by non-linear regression, using the Levenberg-Marquardt algorithm and least squares as loss function. As the Gompertz model follows a non-linear trend, comparisons between estimated parameters in different mussel populations could not be calculated by classical techniques of general linear models. Instead, we used an extra sum of squares, a statistical technique similar to that employed to compare non-linear growth curves (Chen et al., 1992). This technique (Motulsky and Christopoulos, 2004) facilitates comparing growth curves from estimated parameters directly between mussel seed populations, using a set of pairwise contrasts, by an $F$ statistical test: $F=\left[\left(\left(\mathrm{RSS}_{\mathrm{s}}\right)-\left(\mathrm{RSS}_{\mathrm{i}}\right) /\left(\right.\right.\right.$ d.f. $_{\mathrm{s}}-$ d.f. $\left.\left._{\text {. }}\right)\right) /$ $\left(\mathrm{RSS}_{\mathrm{i}} / \mathrm{d}_{\mathrm{f}} \mathrm{f}_{\mathrm{i}}\right)$ ], where $\mathrm{RSS}_{\mathrm{s}}$ and $\mathrm{RSS}_{\mathrm{i}}$ are the residual sum of squares of the curves fitted with and without a parameter shared, respectively, and d.f.s and d.f..$_{\cdot \mathrm{i}}$ represent their degrees of freedom.

All data sets of shell length and dry tissue weight obtained during the entire experimental period (March 2003 to February 2004) were used to calculate allometric coefficients of the relationship between tissue dry weight and length $\left(\mathrm{DW}_{\text {tissue }}=a L^{b}\right)$. Analysis of covariance (ANCOVA) was used to make comparisons between mussel populations using their log-transformed allometric equations (Snedecor and Cochran, 1980).

CI values were compared monthly between populations by ANCOVA, taking into account the initial values. Average values for each phase of the culture were also compared between populations using ANCOVA. Initial values of CI had no significant effect on differences obtained for CI values between mussel populations during their culture (ANCOVA; $p>0.05$ ). A Tukey's post hoc test was used when there was homogeneity of variances; otherwise, a Tamhane post hoc test was applied. Average CI values obtained for both phases of the culture in each mussel population were compared by means of a $t$-test corrected for unequal variance. 
Growth rates were calculated for the entire culture period (March 2003 to February 2004) in units of $\mathrm{mm} \mathrm{month}^{-1}$ and $\mathrm{g} \mathrm{month}^{-1}$, using both replicates of each sample. ANCOVA was used to compare growth rates of mussel populations taking into account the initial length/weight values. Such initial size values had no significant effect on the growth-rate values for both length and weight (ANCOVA; $p>0.27$ ). Tukey's test was used as post hoc test to detect differences between growth rates of mussels.

Three size ranges were established to analyse the size composition of each mussel population at harvest, and were categorized as follows: "mussels below minimum commercial size", "small mussels", and "large mussels", corresponding to mussel sizes $<50 \mathrm{~mm}, 50-70 \mathrm{~mm}$, and $>70 \mathrm{~mm}$, respectively. Frequency values of the latter mussel sizes among experimental populations were compared using a set of pairwise contrasts and contingency tables, and a $\chi^{2}$ test. We applied the Bonferroni correction (Zar, 1984) each time a set of pairwise contrasts was used. The statistical package Statistica 6.0 for data processing was applied.

\section{Results}

\section{Environmental parameters}

Temperature during the test period ranged between minimum winter values of 13 and $14^{\circ} \mathrm{C}$ and a maximum of $19.3^{\circ} \mathrm{C}$ in July/August 2003 (Figure 2a). Salinity varied only slightly during the experimental culture, from a minimum of 34.5 in July/August 2003 to a maximum of 35.3 in September/ October 2003 (Figure 2a). There was a small peak in chlorophyll $a$ between March and May 2003, followed by a major peak, four times higher than the first, in August/September 2003 (2.4 and $8.35 \mu \mathrm{g} 1^{-1}$, respectively; Figure $2 \mathrm{~b}$ ).

\section{Size frequency and growth}

Size frequency distributions of the cultured populations were fitted to unimodal or bimodal equations, depending on the fit (Figure 3). At the onset of the culture, all mussel populations fitted a unimodal curve. From May (Redes mussels), and from June (Miranda and Pindo mussels), distributions better fitted a bimodal equation (Figure 3). The latter pattern lasted until thinning-out, although Pindo mussels gradually attenuated their bimodality and the distribution values fitted a unimodal distribution better in August. This was observed despite the large standard deviation derived from the large tail on the left (Figure 3). After thinning-out, the size distributions of the three mussel populations became more uniform, and all fitted unimodal curves (Figure 3).

Growth in shell length or total dry weight of experimental mussels in Ría de Ares-Betanzos was best described by the Gompertz model (Figure 4a, b). There were no significant differences among asymptotic sizes of shell length curve ( $p>0.05$; Table 1; Figure 4). However, asymptotic weight values were significantly different between the lowest values observed for Pindo mussels $(7.36 \mathrm{~g})$ and the
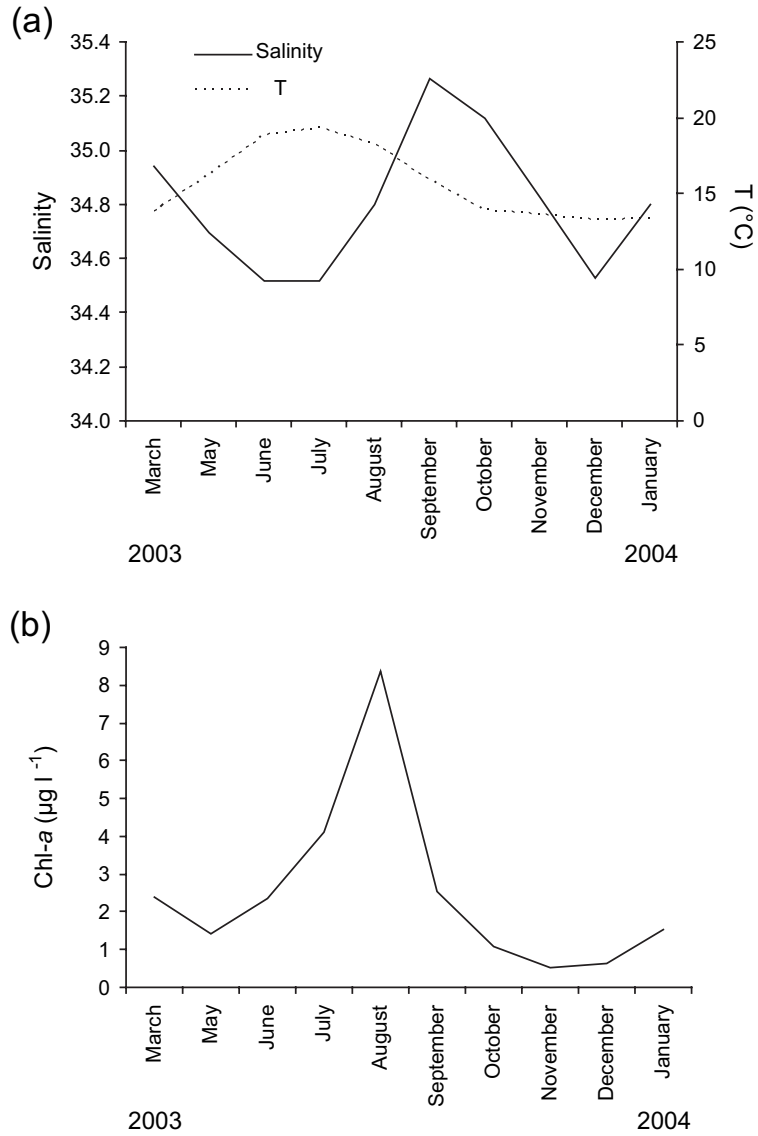

Figure 2. Variations in (a) average temperature $\left({ }^{\circ} \mathrm{C}\right)$ and salinity, and (b) chlorophyll $a\left(\mu \mathrm{g}^{-1}\right)$ during the experimental period, March 2003 to February 2004.

highest for Redes mussels (10.12 $\mathrm{g} ; p<0.05$; Table 1). There were no significant differences in the growth factor $(k)$ or the inflection point $\left(t^{\prime}\right)$ of either shell length or total dry weight growth curves $(p>0.05$; Table 1$)$ between the three mussel seed populations.

Allometric relationships between tissue dry weight and shell length of the mussel populations considering the whole culture data set are illustrated in Figure 5. The curves represent the following equations:

$$
\begin{aligned}
& \text { Redes: } \mathrm{DW}_{\text {total }}=4.265 \times 10^{-6} L^{3.054} \\
& n=61 ; \quad r^{2}=0.955 ; \quad p<0.001 ; \\
& \text { Miranda: } \mathrm{DW}_{\text {total }}=5.794 \times 10^{-6} L^{2.970} \\
& n=63 ; \quad r^{2}=0.986 ; \quad p<0.001 ; \\
& \text { Pindo: } \mathrm{DW}_{\text {total }}=6.879 \times 10^{-6} L^{2.872} \\
& n=61 ; \quad r^{2}=0.965 ; \quad p<0.001
\end{aligned}
$$

Based on ANCOVA analysis, no significant differences were observed between the slopes of the allometric equations $(p>0.05)$. Differences in intercept values were significantly different in all cases, and Pindo and Redes mussels had the lowest and the highest values, respectively $(p<0.05)$. 

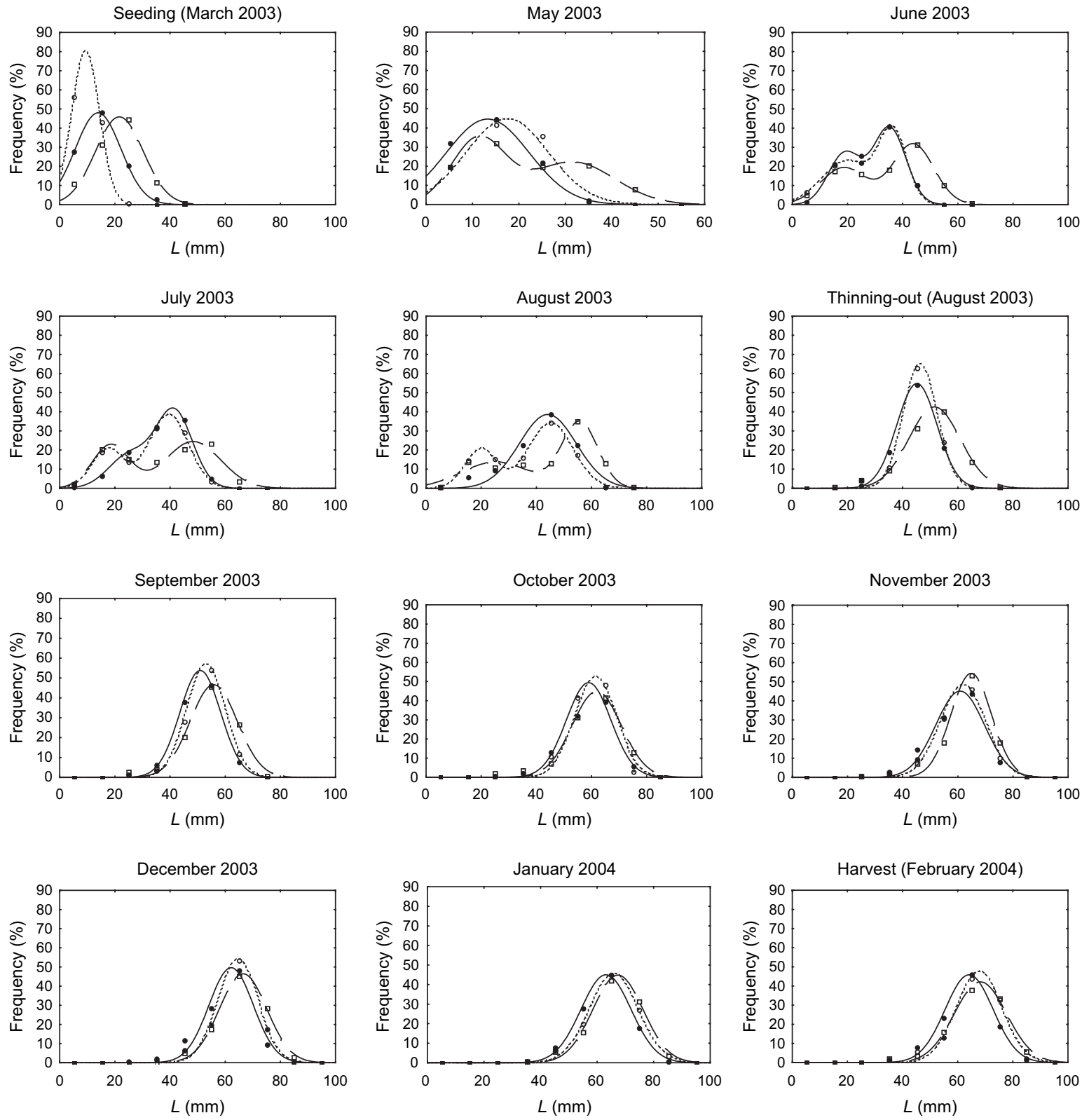

$-\square-$ Redes $-\cdots--$ - Miranda $\longrightarrow$ Pindo

Figure 3. Size frequency distributions for the three mussel populations during the experimental period (March 2003 to February 2004) fitted to unimodal or bimodal equations.

\section{Condition index (CI)}

The CI of mussels varied widely during experimental culture, and a similar pattern was observed for chlorophyll $a$ in the seawater (Figure 6a). Although specific differences were recorded between CI values for the different populations under study, the average values during the whole experimental period (March 2003 to February 2004) were similar for the three populations, between $19 \%$ and $21 \%$ in meat yield ( $p>0.05$; Figure 6a).
In respect of both phases of the experimental culture, from seeding to thinning-out and from thinning-out to harvest, mean CI values were significantly lower during the first phase (March to August 2003) than in the second phase (September 2003 to February 2004), for all mussel populations $(p<0.05$; Figure $6 \mathrm{~b})$. Moreover, during the first phase of culture, mussels from Redes showed significantly higher mean CI values than those from Pindo $(p<0.05$; Figure $6 \mathrm{~b})$. By contrast, during the second phase 

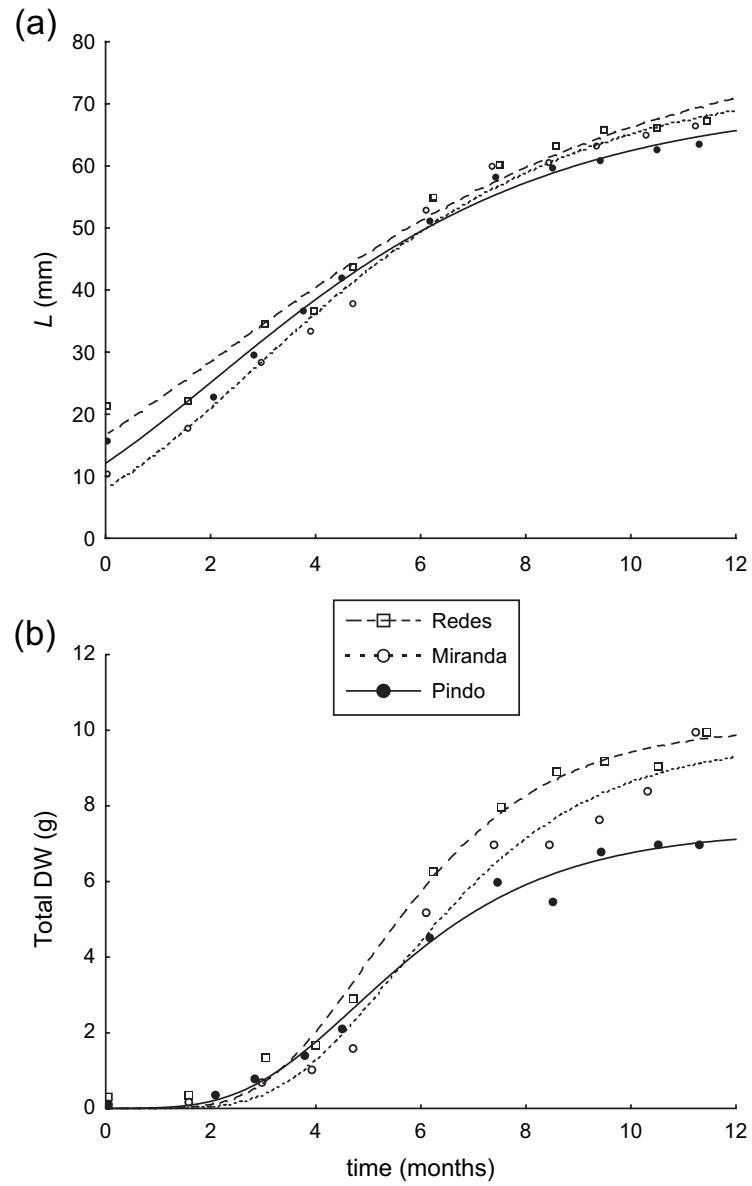

Figure 4. Growth curves for the three mussel populations under experimental culture during the period March 2003 to February 2004 in terms of (a) shell length, and (b) total dry weight. Shell length and total dry weight growth curves were fitted to a Gompertz model.

Table 1. Estimated parameters and coefficients of determination for the growth curves according to a Gompertz model $\left(Y_{t}=Y_{\infty}\left(\mathrm{e}^{\left.-\mathrm{e}^{\left(-k\left(t-t^{\prime}\right)\right.}\right)}\right)\right)$ for the three populations under study, March 2003 to February 2004. All parameters are statistically significant $(p<0.001)$. Significant differences between a population's estimated parameters are marked only against $Y_{\infty}$ for total dry weight values, and are shown with different letters $(p<0.05)$

\begin{tabular}{|c|c|c|c|c|c|c|}
\hline \multirow[b]{2}{*}{ Parameter } & \multicolumn{3}{|c|}{$\begin{array}{l}\text { Value in terms of } \\
\text { shell length }(\mathrm{mm}) \\
\text { per population }\end{array}$} & \multicolumn{3}{|c|}{$\begin{array}{l}\text { Value in terms of } \\
\text { total dry weight }(\mathrm{g}) \\
\text { per population }\end{array}$} \\
\hline & Redes & Miranda & Pindo & Redes & Miranda & Pindo \\
\hline$Y_{\infty}$ & 81.068 & 74.316 & 70.628 & $10.120^{\mathrm{a}}$ & $9.751^{\mathrm{ab}}$ & $7.362^{\mathrm{b}}$ \\
\hline$k$ & 0.206 & 0.282 & 0.267 & 0.519 & 0.469 & 0.469 \\
\hline$t^{\prime}$ & 2.231 & 2.829 & 2.114 & 4.912 & 5.509 & 4.761 \\
\hline$r^{2}$ & 0.978 & 0.989 & 0.988 & 0.992 & 0.979 & 0.966 \\
\hline
\end{tabular}

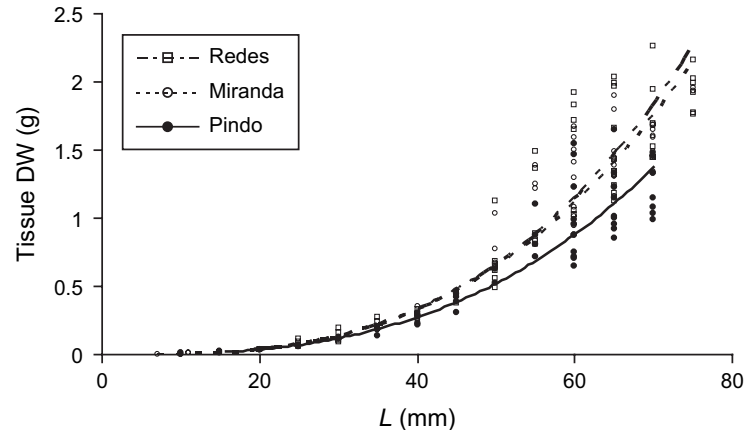

Figure 5. Allometric relationship between tissue dry weight and shell length for the three mussel populations during the period of culture, March 2003 to February 2004.

of culture, there were no significant differences between mean CI recorded for the mussel populations ( $p>0.05)$, although higher variability was reported in all populations.

\section{Growth rates}

Growth rates of cultured mussels differed when shell length and dry weight of the populations were compared. Whereas shell length growth rates $\left(\mathrm{mm}\right.$ month $\left.^{-1}\right)$ showed no significant differences among mussel populations (Figure 7a), weights, i.e. tissue, shell, and total dry weights $\left(\mathrm{g} \mathrm{month}^{-1}\right)$ were significantly lower for Pindo mussels $(p<0.05$; Figure $7 b-d)$. The latter differences in growth rates of mussels cannot be attributed to initial weights, because this factor had no significant effect on growth rate (ANCOVA; $p>0.27$ ).

\section{Commercial sizes at harvest}

Figure 8 illustrates the frequency values of the different mussel sizes categorized at harvest: "mussels below minimal commercial size", "small mussels", and "large mussels". All populations had few mussels below minimum commercial size, between $4.7 \%$ and $7.2 \%(p>0.05$, for Redes and Pindo mussels, respectively). Mussels from Redes and Miranda also had similar proportions of large and small mussels, some $40 \%$ and $50 \%$, respectively $(p>0.05$; Figure 8$)$. However, the percentage of large mussels recorded for the Pindo population was just $26 \%$, significantly less than the percentages recorded for the other two mussel populations ( $p<0.05$; Figure 8 ).

\section{Discussion}

Growth rate represents an integrated indicator of physiological conditions in bivalve molluscs (Sukhotin and Maximovich, 1994; Dame, 1996), and as such it has been used commonly to indicate pollution effects and environmental quality (Dame, 1996). Of the three mussel populations grown in the Ría de Ares-Betanzos, those originating 
(a)

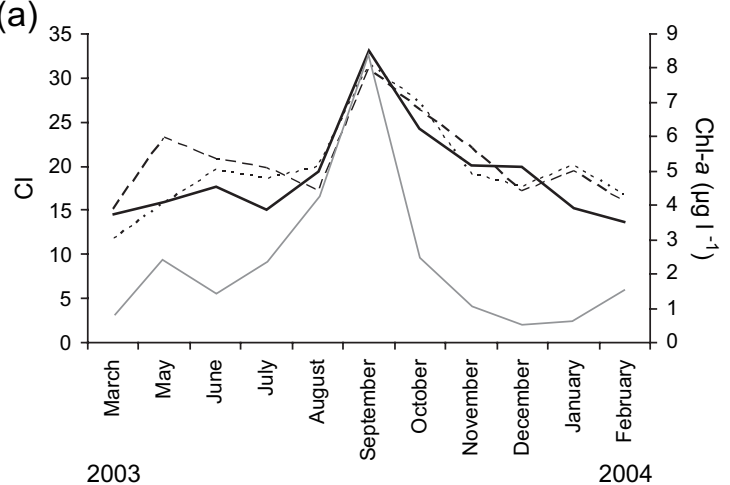

2003

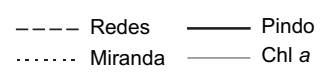

(b)

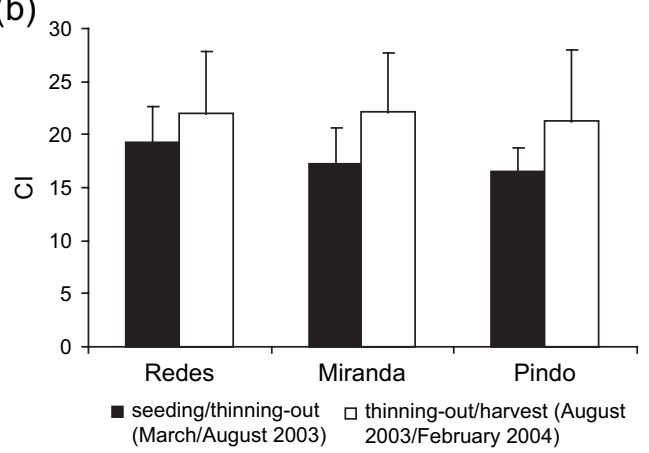

Figure 6. (a) Fluctuations in condition indices for the three mussel populations and variations in mean chlorophyll $a$ in the water column during the culture period, March 2003 to February 2004.

(b) Average condition indices of the three mussel populations for the two phases of the experimental culture, seeding/thinning-out (March to August 2003) and thinning-out/harvest (August 2003 to February 2004).

(a)

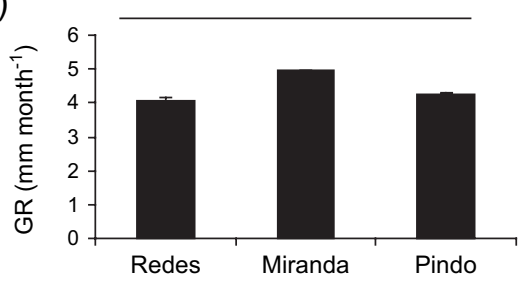

(b)

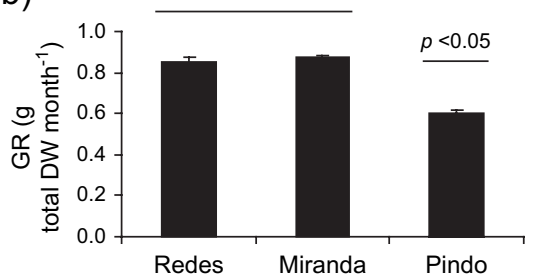

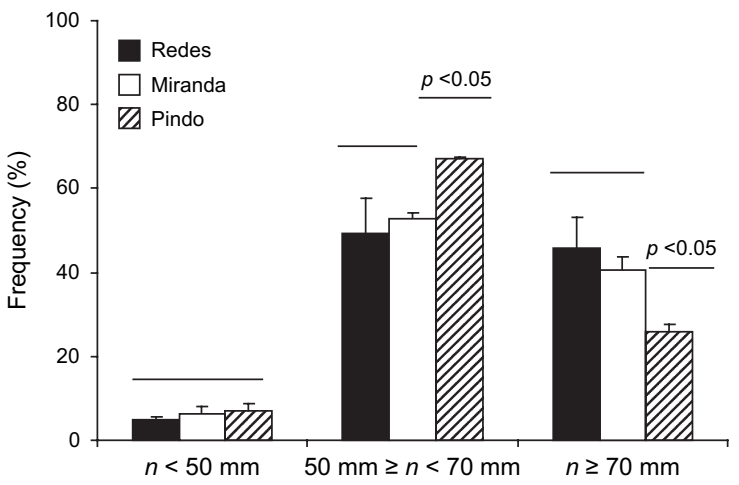

Figure 8. Percentage of mussels $<50 \mathrm{~mm}, 50-70 \mathrm{~mm}$, and $>70 \mathrm{~mm}$ shell length obtained for each population at harvest (in February 2004). Lines drawn at different levels represent significant differences $(p<0.05)$.

from Pindo showed significantly less growth than the other populations (Miranda and Redes). Slow growth has also been reported in other studies when different species of bivalves have been exposed to pollutants (Strömgren, 1982; Strömgren and Bongard, 1987; Salazar and Salazar, 1991; Guolan and Yong, 1995; Soto et al., 2000), specifically hydrocarbons (Strömgren et al., 1986; Le Floch et al., 2003).

Growth in weight was significantly less in the Pindo mussels than in the other populations, so because growth in weight has been reported as more sensitive than growth in length as a response to environmental change (Salazar and Salazar, 1991, 1995), this is the likely reason for the differences in growth rates measured here. Further, for the growth curves fitted here, significant differences were only observed in the weight-adjusted parameters,

(c)

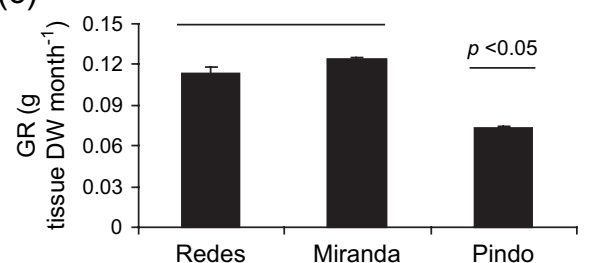

(d)

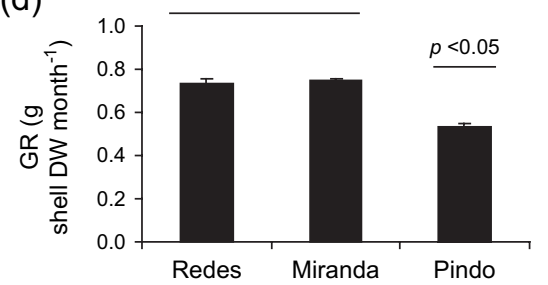

Figure 7. Growth rates (GR) of the three mussel populations during the experimental culture period (March 2003 to February 2004) expressed in terms of (a) shell length, (b) total dry weight, (c) tissue dry weight, and (d) shell dry weight. Lines drawn at different levels represent significant differences $(p<0.05)$. 
for which the lowest asymptotic values of growth were in Pindo mussels and the highest in Redes mussels (Figure 4; Table 1).

Labarta et al. (2005) observed a pollution gradient along the Galician coastline for several mussel recruits commonly exploited for commercial culture on rafts. Such a gradient was based on several physiological and biochemical indicators of stress in the mussels, as well as on hydrocarbon concentrations in soft tissues three months after the Prestige spill, providing information about the degree of exposure to hydrocarbons and the physiological and biochemical response to such exposure. Here we selected three of the mussel populations assessed by Labarta et al. (2005). From the selected populations and based on the results of Labarta et al. (2005), Pindo mussels came from the population with the greatest biochemical alteration at the onset of the experimental culture and from an area with a greater hydrocarbon exposure associated with the spill. The sublethal effects detected at the beginning of the study might last for a long time during experimental culture, perhaps explaining the slower growth rates of Pindo mussels.

Initial differences in length and weight at the beginning of the test might have persisted through to the end of the experiment (Sukhotin and Maximovich, 1994). As our experimental culture followed the same protocols used by the owner company for commercial exploitation, initial values of shell length and weight showed certain heterogeneity between mussel populations (see Material and methods). Nevertheless, statistical analysis of the initial length/weight variability did not detect significant effects on growth rate (ANCOVA; $p>0.27$ ), indicating that the influence of mussel origin was not attributable to initial size differences. In the same way, initial differences in CI had no significant effect on the differences in CI obtained during the culture between mussel populations.

Condition index has been used widely in growth studies as well as in research specifically related to pollution incidence on bivalve molluscs (Bayne, 1985; Guolan and Yong, 1995; Dame, 1996; Hummel et al., 1996; Modassir and Ansari, 2000; Leung and Furness, 2001; Amiard et al., 2004; Boscolo et al., 2004; Duquesne et al., 2004; Pampanin et al., 2005). In our experimental mussel cultures, despite occasional lower CI values for Pindo mussels, there was no clear pattern that persisted for the entire test period. This was the opposite of the pattern observed for growth in weight. CI integrates growth parameters in shell and tissue weights, and is influenced by similar environmental and endogenous factors to tissue dry weight. However, it has been reported that CI is a weak indicator because it is not sensitive to low concentrations of pollutants (Guolan and Yong, 1995; Hummel et al., 1996; Leung and Furness, 2001; Amiard et al., 2004; Boscolo et al., 2004; Duquesne et al., 2004; Pampanin et al., 2005). CI variability is usually attributed to changes in food availability or the gametogenic cycle (Hummel et al., 1996; Amiard et al., 2004; Pampanin et al., 2005).
The slower growth rate recorded throughout the experimental culture of Pindo mussels resulted in a smaller harvest. Commercial market classification of mussels is based on the number of pieces (of mussel meat) per kilogramme of mussels. The lower asymptotic weight values reached at the end of the culture for Pindo mussels $(p<0.05$; Figure 4b) as well as the lower percentage of mussels classified as large $(p<0.05$; Figure 8$)$ resulted in a worse classification in terms of pieces $\mathrm{kg}^{-1}$ for the Pindo population, with associated economic consequences. These results pointed out again a link between the sublethal effects reported at the onset of the culture by Labarta et al. (2005) for Pindo mussels that could persist for longer periods in the experimental culture and result in lower yields.

Results obtained on the growth rates of mussel seed cultured using a raft system as the first generation after the Prestige spill seemed to indicate that the sublethal effects related to previous exposure are manifested in lower yields of mussels from the most affected area (Pindo).

\section{Acknowledgements}

We thank H. Regueiro, M. García, B. González, L. Nieto, and O. Fernández-Rosende for technical assistance, and PROINSA employees for their help in sampling. We also greatly appreciate the contribution of M. H. Salazar for his review and helpful comments on an early draft that significantly improved the final paper. The study was supported by contract-project PROINSA, Code CSIC 2004448, Galicia PGDIT03RMA13E.

\section{References}

Amiard, J. C., Bacheley, H., Barillé, A. L., Barillé, L., Geffard, A., and Himery, N. 2004. Temporal changes in nickel and vanadium concentrations and in condition index and metallothionein levels in three species of molluscs following the "Erika" oil spill. Aquatic Living Resources, 17: 281-288.

Babarro, J. M. F., Labarta, U., and Fernández-Reiriz, M. J. 2003. Growth patterns in biomass and size structure of Mytilus galloprovincialis cultivated in the "Ría de Arousa" (north-west Spain). Journal of the Marine Biological Association of the UK, 83: 151-158.

Bayne, B. L. 1985. Ecological consequences of stress. In The Effects of Stress and Pollution on Marine Animals, pp. 141-157. Ed. by B. L. Bayne, D. A. Brown, K. Burns, D. R. Dixon, A. Ivanovici, D. R. Livingston, D. M. Lowe, M. N. Moore, A. R. D. Stebbing, and J. Widdows. Praeger Publishers, New York. 384 pp.

Bayne, B. L., Holland, D. L., Moore, M. N., Lowe, D. M., and Widdows, J. 1978. Further studies on the effects of stress in the adult on the eggs of Mytilus edulis. Journal of the Marine Biological Association of the UK, 58: 825-841.

Boscolo, R., Cacciatore, F., Berto, D., Marin, M. G., and Giani, M. 2004. Contamination of natural and cultured mussels (Mytilus galloprovincialis) from the northern Adriatic Sea by tributyltin and dibutyltin compounds. Applied Organometallic Chemistry, 18: 614-618.

Box, G. E. P., Hunter, W., and Hunter, J. S. 1989. Estadística para Investigadores. Introducción al Diseño de Experimentos, 
Análisis de Datos y Construcción de Modelos. Ed by S.A. Reverté. Barcelona. 675 pp. (in Spanish). From the original English version: Statistics for Experimenters. An Introduction to Design, Data Analysis and Model Building. John Wiley \& Sons, Inc.

Chen, Y., Jackson, D. A., and Harvey, H. H. 1992. A comparison of von Bertalanffy and polynomial functions in modelling fish growth data. Canadian Journal of Fisheries and Aquatic Sciences, 49: 1228-1235.

Dame, R. F. 1996. Bivalves as components of ecosystem health. In The Ecology of Marine Bivalves. An Ecosystem Approach, pp. 213-226. Ed. by R. F. Dame. CRC Marine Science Series, CRC Press, Boca Raton, FA. 254 pp.

Duquesne, S., Liess, M., and Bird, D. J. 2004. Sublethal effects of metal exposure: physiological and behavioural responses of the estuarine bivalve (Macoma balthica). Marine Environmental Research, 58: 245-250.

Freeman, K. R. 1974. Growth, mortality and seasonal cycle of Mytilus edulis in two Nova Scotian embayments. Technical Report 500, Department of the Environment, Fisheries and Marine Service, Canada. 112 pp.

Guolan, H., and Yong, W. 1995. Effects of tributyltin chloride on marine bivalve mussels. Water Research, 29: 1877-1884.

Hummel, H., Amiard-Trique, C., Bachelet, G., Desprez, M., Marchand, J., Sylvand, B., Amiard, J. C., Rybarczyk, H., Bogaards, R. H., Sinke, J., De Wit, Y., and De Wolf, L. 1996. Sensitivity to stress of the estuarine bivalve Macoma balthica from areas between the Netherlands and its southern limits (Gironde). Journal of Sea Research, 35(Suppl. 4): 315-321.

Labarta, U., Fernández-Reiriz, M. J., Garrido, J. L., Babarro, J. M. F., Bayona, J. M., and Albaigés, J. 2005. Response of mussel recruits to hydrocarbon pollution from the Prestige oil spill along the Galicia coast. A biochemical approach. Marine Ecology Progress Series, 302: 135-145.

Le Floch, S., Guyomarch, J., Merlin, F., Børseth, J. F., Le Corre, P., and Lee, K. 2003. Effects of oil and bioremediation on mussel (Mytilus edulis L.). Environmental Technology, 24: $1212-1219$.

Leung, K. M. Y., and Furness, R. W. 2001. Metallothionein induction and condition index of dogwhelks Nucella lapillus (L.) exposed to cadmium and hydrogen peroxide. Chemosphere, 44: $321-325$

Livingston, D. R. 1985. Biochemical measurements. In The Effects of Stress and Pollution on Marine Animals, pp. 81-134. Ed. by B. L. Bayne, D. A. Brown, K. Burns, D. R. Dixon, A. Ivanovici, D. R. Livingstone, D. M. Lowe, M. N. Moore, A. R. D. Stebbing, and J. Widdows. Praeger Publishers, New York. 384 pp.

Modassir, Y., and Ansari, A. 2000. Effect of petroleum hydrocarbon on physiological and biochemical parameters in an estuarine clam (Paphia malabarica). Fishery Technology, 37: 40-45.

Motulsky, H., and Christopoulos, A. C. 2004. Fitting Models to Biological Data using Linear and Nonlinear Regression: a Practical Guide to Curve Fitting. Oxford University Press, Oxford. $351 \mathrm{pp}$.
Pampanin, D. M., Volpato, E., Marangon, I., and Nasci, C. 2005. Physiological measurements from native and transplanted mussel (Mytilus galloprovincialis) in the canals of Venice. Survival in air and condition index. Comparative Biochemistry and Physiology, 140A: 41-52.

Pérez Camacho, A., González, R., and Fuentes, J. 1991. Mussel culture in Galicia (N.W. Spain). Aquaculture, 94: 263-278.

Pérez Camacho, A., and Labarta, U. 2004. Rendimientos y producción del mejillón: bases biológicas para la innovación. In Bateeiros, Mar, Mejillón. Una Perspectiva Bioeconómica. Ed. by Centro de Investigación Económica y Financiera. Fundación Caixa Galicia. ISBN: 84-95491-69-9. 262 pp.

Ratkoskwy, D. A. 1990. Handbook of Nonlinear Regression Models. Ed. by D. B. Owen, R. G. Cornell, W. J. Kennedy, A. M. Kshirsagar, and E. G. Schilling. Marcel Dekker, Inc., New York. 241 pp.

Salazar, M. H., and Salazar, S. M. 1991. Assessing site-specific effects of TBT contamination with mussel growth rates. Marine Environmental Research, 32: 131-150.

Salazar, M. H., and Salazar, S. M. 1995. In-situ bioassays using transplanted mussels. 1. Estimating chemical exposure and bioeffects with bioaccumulation and growth. In Environmental Toxicology and Risk Assessment, 3, pp. 216-241. Ed. by J. S. Hughes, G. R. Biddinger, and E. Mones. American Society for Testing and Materials, Philadelphia. 408 pp.

Snedecor, G. W., and Cochran, W. G. 1980. Statistical Methods. Iowa State University Press, Ames, Iowa. 507 pp.

Soto, M., Ireland, M. P., and Marigómez, I. 2000. Changes in mussel biometry on exposure to metals: implications in estimation of metal bioavailability in "Mussel-Watch" programmes. Science of the Total Environment, 247: 175-187.

Strömgren, T. 1982. Effect of heavy metals ( $\mathrm{Zn}, \mathrm{Hg}, \mathrm{Cu}, \mathrm{Cd}, \mathrm{Pb}$, $\mathrm{Ni})$ on the length growth of Mytilus edulis. Marine Biology, 72: $69-72$.

Strömgren, T., and Bongard, T. 1987. The effect of tributyltin oxide on growth of Mytilus edulis. Marine Pollution Bulletin, 18(Suppl. 1): 30-31.

Strömgren, T., Nielsen, M. V., and Ueland, K. 1986. Short-term effect of microencapsulated hydrocarbons on shell growth of Mytilus edulis. Marine Biology, 91: 33-39.

Sukhotin, A. A., and Maximovich, N. V. 1994. Variability of growth rate in Mytilus edulis L. from the Chupa Inlet (the White Sea). Journal of Experimental Marine Biology and Ecology, 176: 15-26.

Widdows, J. 1978. Physiological indices of stress in Mytilus edulis. Journal of the Marine Biological Association of the UK, 58: $125-142$.

Widdows, J., Donkin, P., Staff, F. J., Matthiessen, P., Law, R. J., Allen, Y. T., Thain, J. E., Allchin, C. R., and Jones, B. R. 2002. Measurement of stress effects (scope for growth) and contaminant levels in mussels (Mytilus edulis) collected from the Irish Sea. Marine Environmental Research, 53(Suppl. 4): 327-356.

Zar, J. H. 1984. Statistical Analysis. Prentice-Hall, Englewood Cliffs, NJ. 718 pp. 